\title{
CDISC SDTM Mode of Disease Transmission Terminology
}

National Cancer Institute

\section{Source}

National Cancer Institute. CDISC SDTM Mode of Disease Transmission Terminology. NCl Thesaurus. Code C127265.

Terminology associated with the mode of disease transmission codelist of the Clinical Data Interchange Standards Consortium (CDISC) Study Data Tabulation Model (SDT M). 